\title{
Meiotic Studies in Some Species of Pennisetum (L.) Rich. (Poaceae)
}

\author{
D. M. Sujatha, V. Manga, M. V. Subba Rao and J. S. R. Murty \\ Department of Botany, Andhra University, Waltair 530003 , India
}

Accepted November 28, 1988

The genus Pennisetum is a member of the family Poaceae (Gramineae) and comprises several species distributed mainly in tropical and subtropical regions. It constitutes a heterogenous assemblage of species that are widely divergent from one another in growth, habit and morphological characters.

Besides $P$. americanum ( $P$. typhoides, pearl millet), which is cultivated as a grain crop and $P$. purpureum, a common fodder grass, several others are valued as soil binders $(P$. orientale, $P$. clandestinum) and as ornamentals ( $P$. setaceum, $P$. divisum, $P$. villosum). Several of the wild species are resistant to diseases like rust, smut and ergot.

The genus covers four basic chromosome types viz. $x=5,7,8$ and 9 . Of all the species included in this genus, $P$. americanum has been the subject of extensive cytogenetic studies (see Pantulu and Krishna Rao for a review, 1981) because of its importance as a grain crop. Cytological information on other species is relatively meagre, and in some cases is restricted to chromosome reports only. Several cytotypes were also known for some of the species (like $P$. orientale, $P$. polystachion).

As a part of the biosystematic studies in this genus, twelve species were subjected to detailed meiotic analyses and the results are presented in this article, with the aim of contributing information to a better understanding of the interspecific relationships and/or evolutionary statuses within the genus.

\section{Materials and methods}

For the study of PMC meiosis, young inflorescences were fixed in $1: 3$ acetic alcohol, and stored in $70 \%$ alcohol. Pollen sterility was estimated from pollen grains stained with $2 \%$ acetocarmine and completely filled and stained grains were considered as fertile ones. The materials either in the form of culms/seed were obtained from GRU Unit of ICRISAT, Patancheru.

\section{Results}

Frequencies of the different chromosomal associations and mean chiasma frequencies at diakinesis and MI are presented in Table 1.

$P$. americanum (Syn. P. typhoides): During meiosis, presence of seven bivalents was a common feature both at diakinesis and metaphase I (Plate I, Figs. 1, 2). An average of 13.5 chiasmata per cell at diakinesis and 13.1 at metaphase I (Table 1) were observed in the present inbred lines. The bivalents exhibited regular orientation at metaphase I and disjunction at anaphase I. Further meiosis was regular and pollen fertility was $92 \%$.

$P$. violaceum: The 14 chromosomes of the diploid complement formed into 7 bivalents regularly (Plate I, Fig. 3) and among these ring bivalents were more prevalent both at diakinesis and metaphase $I$ respectively and the mean chiasma frequencies being 13.4 and 12.5 at these two stages. Majority of the cells (98\%) exhibited equal segregation (7-7) of chromosomes to 


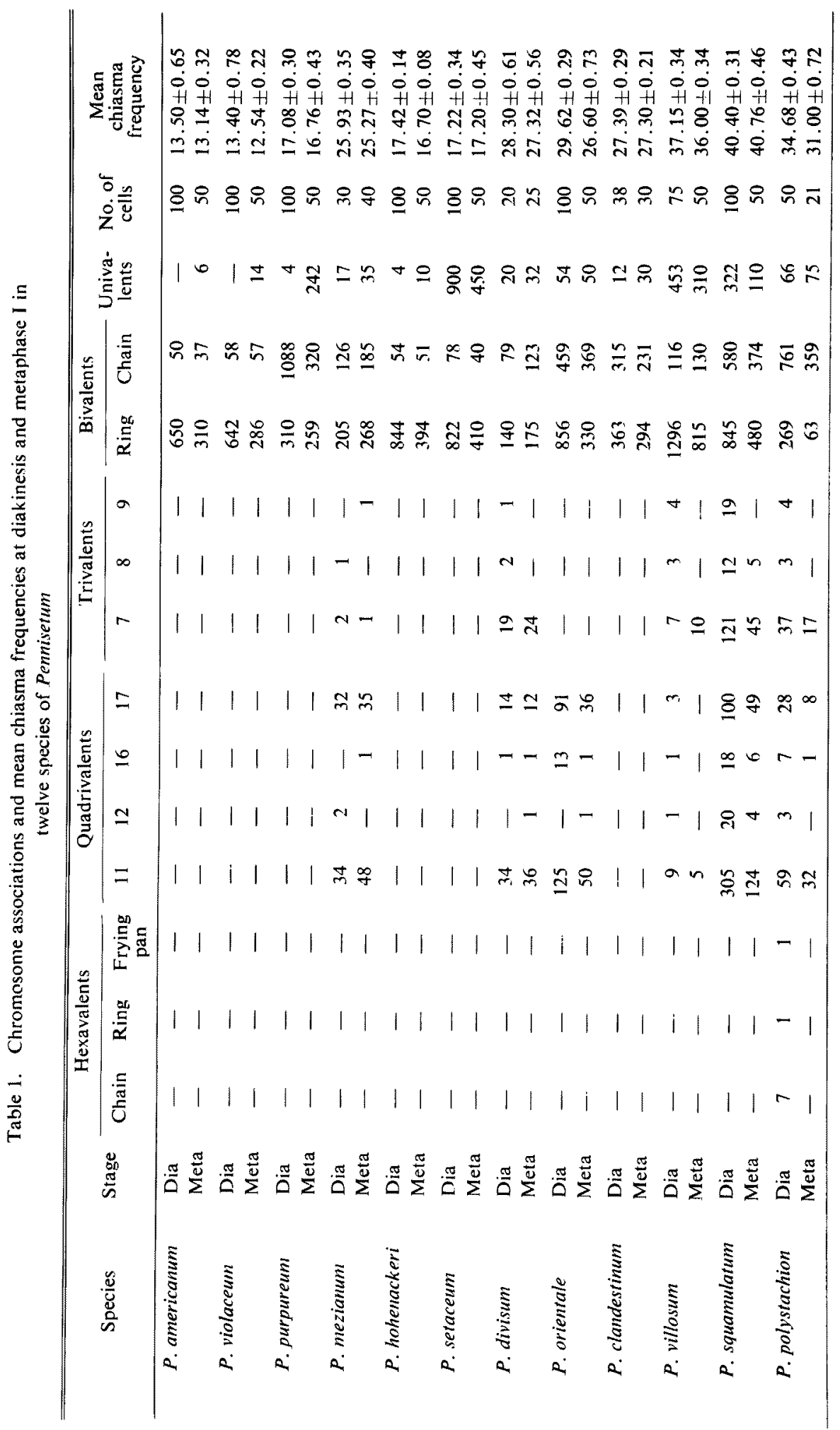


the poles at anaphase I while in the remaining, it was 8-6. The second meiotic divison was normal and pollen fertility was $86.3 \%$

$P$. purpureum: This species has 28 chromosomes in its pollen mother cells and showed regular formation of bivalents at diakinesis and metaphase $I$. The number of bivalents ranged from 13 to 14 at diakinesis and 7-14 at metaphase I (Plate I, Figs. 4, 5). At diakinesis two bivalents were observed to organize one nucleolus each. The two nucleoli differed in their size. The average chiasmata per cell were 17.08 and 16.76 at the two stages respectively. At anaphase $I$, in addition to the equal segregation of chromosomes $(66 \%$, Plate I, Fig. 6$)$, other types such as 12-16, 13-15, 11-17 were also observed. Laggards ranging from 1-4 were observed at first telophase in 34 percent of the cells. Tripolar spindles were encountered in $6 \%$ of the cells and laggards ranging from 0-3 (Plate I, Fig. 7) were observed at telophase II. The pollen fertility was about $78 \%$.

P. mezianum: The 32 chromosomes of the genome associated into bivalents as well as multivalents. The multivalents ranged from 0-6 with an average of two per cell and they included both trivalents and quadrivalents. The multivalent configurations included types 7 $(2.8 \%), 8(1.4 \%), 11(47.89 \%), 12(2.82 \%)$ and $17(45.07 \%)$ at diakinesis and types $7,11,16$ and 17 at metaphase I respectively (Table 1; Plate I, Figs. 8, 9). The ring quadrivalents were more frequent at both the stages. The mean chiasma frequency per cell was 25.93 at diakinesis and 25.27 at metaphase I. Equal distribution of chromosomes (16-16) at anaphase I was more frequent $(95 \%)$ than the other types like 14-18 (5\%). Delayed disjunction of bivalents as well as quadrivalents and laggard formation were observed in a very low percentage of the PMCs (Plate I, Fig. 10). The second division was regular and the pollen fertility was 71.7 percent.

$P$. hohenackeri: This was found to be a diploid with $2 \mathrm{n}=18$ chromosomes which formed into 9 bivalents (Plate I, Figs. 11, 12; Table 1) with a mean chiasma frequency of 17.42 and 16.7 per cell at diakinesis and metaphase I. Despite the regular formation of bivalents and equal (9-9) distribution of chromosomes at anaphase I, the observed pollen fertility was only 66.8 percent. No abnormalities were observed during the second meiotic division.

$P$. setaceum: The 27 chromosomes present in this species invariably formed 9 bivalents and 9 univalents both at diakinesis and metaphase I (Plate II, Fig. 1). In 45.71 percent of the cells at metaphase $\mathrm{I}$, all the 9 univalents were observed to co-orient along with the bivalents (Plate II, Fig. 2).

The chromosomal segregations varied from $14-13$ to $18-9$ of which the former occurred with a high frequency $(45 \%)$. Laggards varying in number from $1-4$ were observed in $42.85 \%$ of the cells (Plate II, Fig. 3) at telophase I. Cells at telophase II also showed 1-4 laggards in 60 percent of the cells. A very large proportion of the microspore tetrads showed micronuclei (Plate-II, Fig. 4). The pollen fertility was 57.49 percent. All the progeny plants raised from the seed had $2 \mathrm{n}=27$ chromosomes like the parent plants.

$P$. divisum: This species had 36 chromosomes. In addition to the bivalents, trivalents and quadrivalents were also observed at diakinesis and metaphase I (Plate-II, Figs. 5, 6). The number of quadrivalents ranged from 1-8. Among the recognised types of multivalent associations, types 7 and 11 were more $(48 \%$ and $27 \%$ ) at diakinesis than others viz. type 8 $(2.8 \%)$, type $9(1.4 \%)$, type $16(1.4 \%)$ and type $17(19.71 \%)$ (Table 1$)$. At anaphase I, 54 percent of cells showed 18-18 segregation of chromosomes while the other types included 17-19 $(36 \%)$ 16-24 (10\%). Laggards at telophase I were observed only in 4 percent of cells and pollen fertility was 71.2 percent.

P. orientale: As in $P$. divisum, this species also had $2 n=36$ chromosomes which associated to form into bivalents, trivalents and quadrivalents. The quadrivalent frequency was higher at diakinesis than at metaphase I (Table 1). Among the quadrivalent configurations observed (Darlington 1937), type 11 occurred with a high frequency $(54 \%)$ followed by types $17(41 \%)$ 

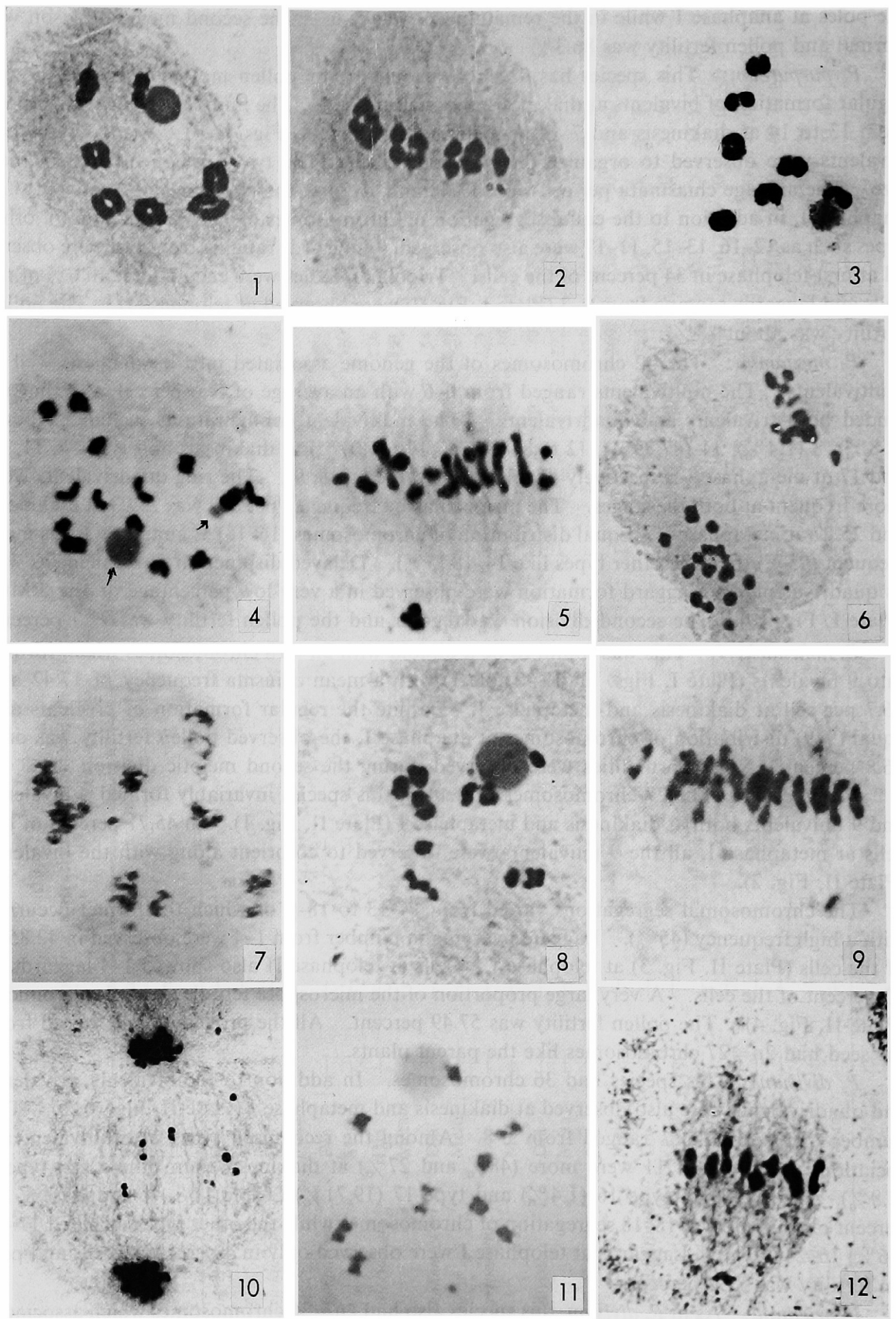
and $16(5 \%)$ (Plate II, Figs. 7, 8, 9). Anaphase I included the predominant 18-18 segregation $(86 \%)$ as well as $17-19$ and $20-16$ types. At telophase I, 1-4 laggards were observed in 12 percent of the cells (Plate II, Fig. 10). The pollen fertility observed was 47.4 percent.

$P$. clandestinum: This species also showed $2 n=36$ chromosomes as in the two earlier ones. 98 percent of the cells at diakinesis and 92 percent as metaphase I showed regular formation of 18 bivalents (Plate II, Figs. 11,12) in P. clandestinum. The mean chiasma frequency per PMC at these two stages was nearly the same 27.3 . In most $(91 \%)$ of the cells at anaphase I, 18-18 distribution of chromosomes was observed and in the rest it was 17-19. The pollen fertility was 75.47 per cent.

$P$. villosum: The chromosome number in this species was $2 n=45$. Multivalent associations other than trivalents and quadrivalents were not observed. Among the trivalents observed at diakinesis, type 7 was more prevalent $(50 \%)$ followed by types $9(28.57 \%)$ and $8(21-43 \%)$. The number of quadrivalents per PMC varied from 0-2 at diakinesis and was either none or one at metaphase I (Plate III, Figs. 1, 2). Among the quadrivalent configurations at diakinesis (types $11,12,16$ and 17$)$, type 11 occurred with the highest frequency $(64.28 \%$ ), while the metaphase I data revealed the occurrence of only type 11. The mean chiasma frequencies at diakinesis and metaphase I were 37.15 and 36 per cell respectively.

Segregation of chromosomes at anaphase I varied widely. 41 percent of the cells exhibited 23-22 distribution while others showed $21-24(32 \%), 20-25,22 \%)$ and $19-26(5 \%)$. The pollen fertility was 54 per cent.

P. squamulatum: Highest chromosomal associations observed in this species $(2 \mathrm{n}=54)$ during the first meiotic division were quadrivalents and their number varied from $1-9$ per PMC (Plate III, Figs. 3, 4). In 10 per cent of the cells scored, 9 quadrivalents and 9 bivalents were observed. Among the multivalent configurations (Darlington 1937) observed at diakinesis and metaphase I, type $7(79.6$ and $90 \%)$ and type $11(68 \%$ and $67.7 \%$ ) were more frequent. Other configurations included types $8,9,12,16$ and 17 . Of the 100 cells observed at anaphase 1 equal segregation (27-27) of chromosomes was more frequent compared to the other types like 26-28, 25-29 and 24-30. Of the 12 species involved in the present study $P$. squamulatum exhibited a very high frequency of laggards (44\%) (Plate III, Fig. 5). The pollen fertility was 68.5 per cent.

$P$. polystachion: This species also had $2 \mathrm{n}=54$ chromosomes like $P$. squamulatum but differed from it in showing association of chromosomes higher than quadrivalents i.e. hexavalents, both at diakinesis and metaphase I (Plate III, Figs. 6, 7, 8). Three types of hexavalent configurations viz., ring $(11.11 \%)$, ring-rod $(11.11 \%)$ and chains $(77.78 \%)$ were observed at diakinesis. Among the total seven types of bivalents and quadrivalent associations observed at diakinesis (types 7, 8,9,11,12,16 and 17; Darlington 1937), types 7 and 11 were more frequent $(84 \%$ and $60.82 \%)$. At metaphase I hexavalents occurred with a very low frequency. The mean chiasma frequencies were 35.2 and 31.0 at diakinesis and metaphase I respectivly.

Plate 1

Figs. 1-12. Meiotic stages in the species of Pennisetum. $\times 1800 . \quad 1$, diakinesis in P. americanum showing 7 bivalents. 2, metaphase $I$ in $P$. americanum showing 7 bivalents at the equatorial region. 3, diakinesis in $P$. violaceum showing 7 bivalents. 4, diakinesis in $P$. purpureum showing 14 bivalents and two nucleoli (arrows). 5, metaphase $I$ in $P$. purpureum showing 12 bivalents and 4 univalents. 6, anaphase $I$ in $P$. purpureum showing 14-14 segregation. 7 , telophase II in $P$. purpureum showing in one of the dyads, 3 groups of chromosomes due to the formation of a tripolar spindle. 8 , diakinesis in $P$. mezianum showing 4 quadrivalents and 8 bivalents. 9 , metaphase 1 in $P$. mezianum showing 3 quadrivalents and 10 bivalents. 10 , telophase $I$ in $P$. mezianum showing laggards. 11 , diakinesis in $P$. hohenackeri showing 9 bivalents. 12 , metaphase $I$ in $P$. hohenackeri showing 9 bivalents. 

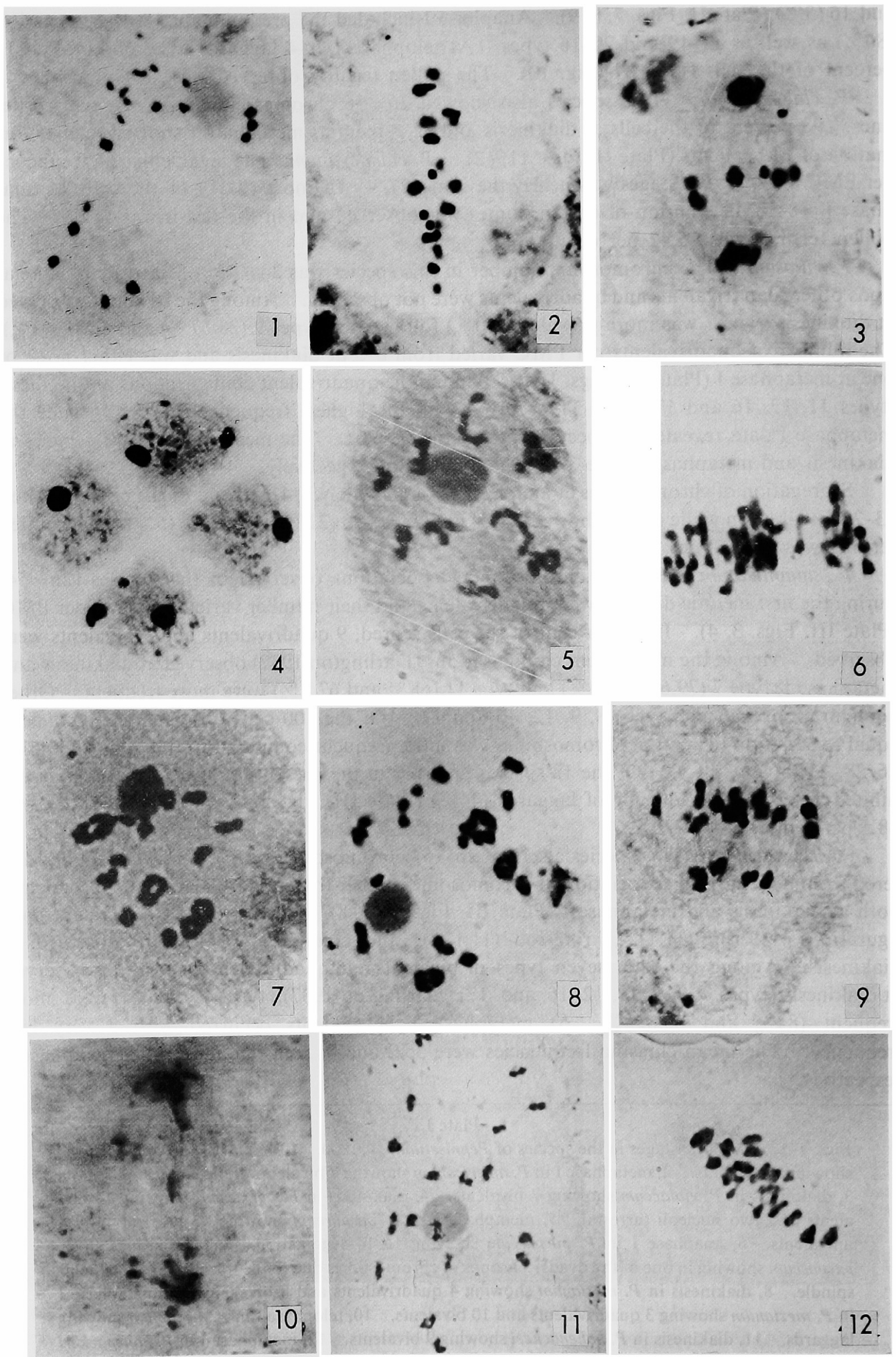
Equal segregation of chromosomes at anaphase I was observed in 44 percent of cells and the other types included 26-28, 25-29, 24-30. Laggards were present in 15\% of the cells at telophase I (Plate III, Fig. 9). The pollen fertility was 36.06 per cent.

\section{Discussion}

From an overall view of the cytological features observed in 12 species under study, $P$. americanum and $P$. violaceum showed higher percentage of pollen fertility associated with the absence of higher chromosomal associations and meiotic abnormalities. Of the two species, $P$. americanum showed maximum pollen fertility which is expected due to the direct selection it has been subjected to as the important millet cultivated for its grain. The present study indicates a very close similarity between $P$. americanum and $P$. violaceum in their cytological behaviour. It is difficult to distinguish morphologically these two species from one another except for the deciduous nature of spikelets and the exerted nature of grains in $P$. violaceum. The three species $P$. americanum, $P$. violaceum and $P$. purpureum were earlier included under the section Penicillaria (Stapf and Hubbard 1934) while Clayton (1972) considered $P$. violaceum as a separate species. Brunken (1977) treated these three species under a single section, Pennisetum, but considered $P$. violaceum as a subspecies of $P$. americanum. From the results of the present study also, Brunken's inclusion of these two, as subspecies of $P$. americanum rather than as two separate species seems justifiable.

$P$. purpureum with nearly $80 \%$ stainable pollen, 14 bivalents, absence of higher associations, but with meiotic abnormalities could be considered as on allotetraploid, derived from species with basic chromosome number 7 and having two genomes as suggested by the earlier studies (Karishnaswamy 1951, Krishnaswamy and Rahman 1953, Khan and Rahman 1963, Ramulu 1968, Sethi et al. 1970, Rangaswamy 1972, Pantulu 1967).

The situation seems to be different in $P$. mezianum with $2 \mathrm{n}=32$ chromosomes in which both higher associations and abnormalities were present but with 72 percent stainable pollen. Though the number of multivalents ranged from 0-6 with an average of two per cell, the bivalents were more prevalent. Swaminathan and Nath (1956) reported a tetraploid cytotype $(2 n=32)$ of this species, showing prevalency of bivalents and with a mean of 0.85 IV per cell, while Rangaswamy (1972) observed a maximum of 7 IVs which is indicative of its autotetraploid nature. On the other hand, Jauhar (1981) observed that $P$. mezianum tetraploid could have been the result of hybridization between two cytotypes following chromosome doubling. Hence it can be an intervarietal autotetraploid (Stebbins 1957) or an interspecific autoploid (Jauhar and Joshi 1969). Despite these two controversies, this species can be logically assumed to represent tetraploidy corresponding to $x=8$ type.

The other eight species used in the study having chromosome numbers $n=9$ or multiples of that are to be conceived as having been dervied from an ancetstral form with $x=9$.

Thus $P$. hohenackeri is a diploid form which is in agreement with the earlier chromosome

\section{Plate II}

Figs. 1-12. Some stages of meiosis in the species of Pennisetum. $\times 1700.1$, diakinesis in $P$. setaceum showing 9 bivalents and 9 univalents. 2, metaphase $I$ in $P$. setaceum showing 9 bivalents and 9 univalents. 3, telophase 1 in $P$. setaceum showing laggards. 4, microspore tetrad in $P$. sefaceum showing micronuclei. 5 , diakinesis in $P$. divisum showing 8 quadrivalents, 1 trivalent and a univalent. 6 , metaphase 1 in $P$. divisum showing quadrivalents. 7 , diakinesis in $P$. orientale showing 5 quadrivalents and 8 bivalents. 8 , diakinesis in $P$. orientale showing 3 quadrivalents, 10 bivalents and 4 univalents. 9 , metaphase $I$ in $P$. orientale showing 4 quadrivalents and 10 bivalents. 10 , telophase $I$ in $P$. orientale showing laggards. 11 , diakinesis in $P$. clandestinum showing 18 bivalents. 12 , metaphase $I$ in $P$. clandestinum showing 18 bivalents. 
number reports (Janaki Ammal cited in Darlington and Janaki Ammal 1945, Hrishi 1952, Rangaswamy 1972, Cristopher and Abraham 1967). The low pollen fertility in this species $(67 \%)$ could not be attributed to any meiotic phenomenon since the meiosis was not aberrant. In spite of the $33 \%$ pollen sterility the seed set was very high, which could be due to its obligate apomictic nature (Shanthamma and Narayan 1977).
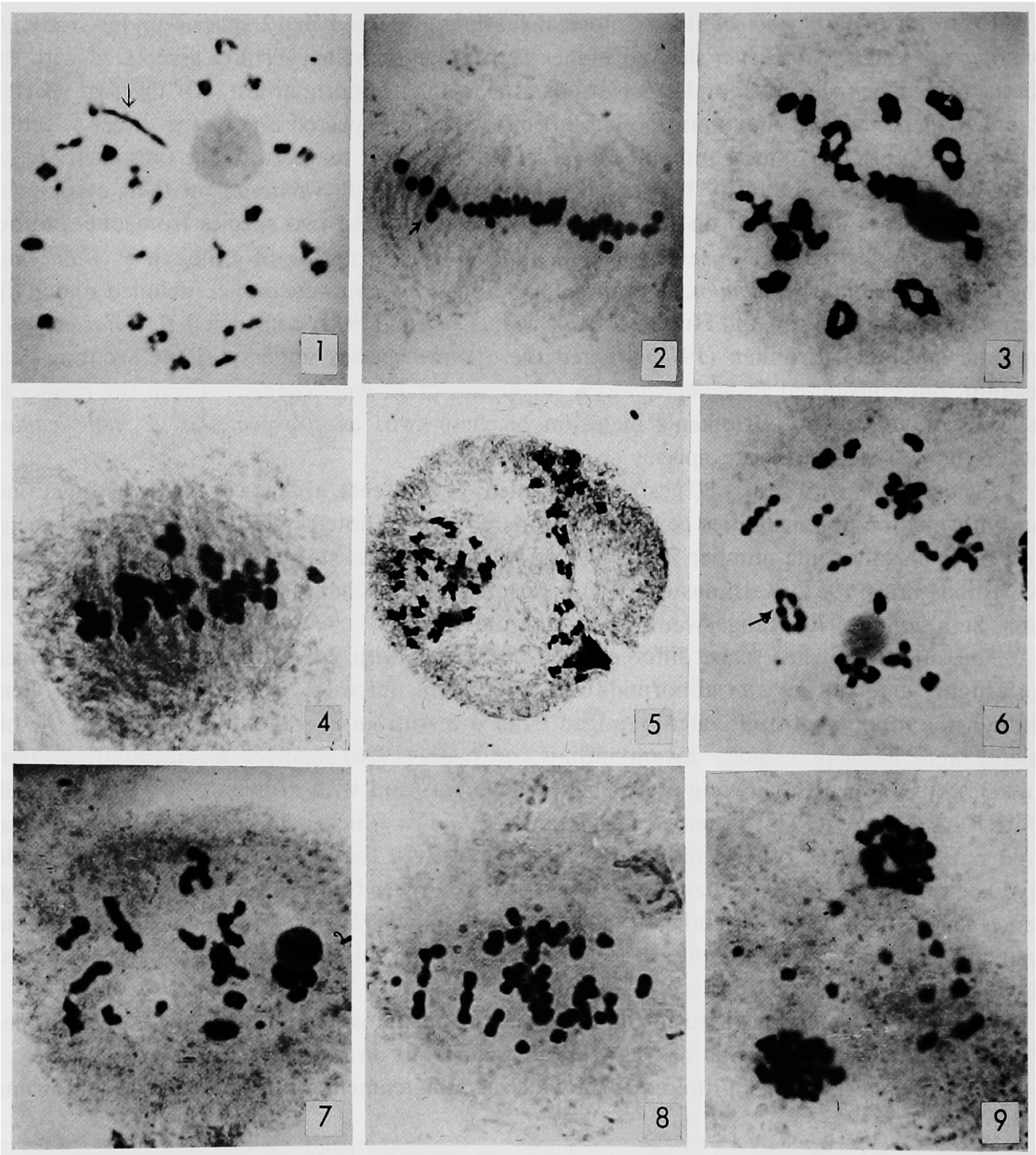

Plate III

Figs. 1-9. Meiotic stages in the species of Pennisetum. $\times 1700.1$, diakinesis in P. villosum showing one quadrivalent, 18 bivalents and 5 univalents. 2, metaphase $I$ in $P$. villosum showing one trivalent, 19 bivalents and 4 univalents. 3 , diakinesis in $P$. squamulatum showing 8 quadrivalents and 11 bivalents. 4, metaphase $I$ in $P$. squamulatum showing quadrivalents, trivalents and univalents. 5 , second division in $P$. squamulatum showing asynchrony. 6, diakinesis in $\boldsymbol{P}$. polystachion showing one hexavalent, quadrivalents, trivalents, bivalents and univalents. 7 , diakinesis in $P$. polystachion showing a chain of six chromosomes, 7 quadrivalents, 1 trivalent, 8 bivalents and 1 univalent. 8, metaphase $\mathrm{I}$ in $P$. polystachion showing prevalency of bivalents and univalents. 9 , telophase I in $P$. polystachion showing laggards. 
$P$. setaceum is obviously an allotriploid in which meiotic abnormalities were present but with no higher associations. The occurrence of 9 IIs +9 Is indicate its allotriploid nature having a diploid and a haploid genome as has also been inferred by Simpson and Bashaw (1969), Narayan (1951), Rahman et al. (1962) and Rangaswamy (1972).

According to Jauhar (1981), $P$. setaceum resembles some strains of $P$. typhoides in its leaf characters, while it resembles $P$. orientale in earhead characters and thus $P$. setaceum could be a hybrid between $P$. typhoides $\times P$. orientale. The meiotic behaviour of $\mathrm{F}_{1}$ hybrid between $\boldsymbol{P}$. setaceum $\times \boldsymbol{P}$. typhoides, revealed the homeology between 3 chromosomes of typhoides to those of $P$. setaceum (Hanna 1979) and the homeology of the other chromosomes can well be revealed only from hybrids that should be produced involving $P$. setaceum and $P$. orientale.

Khosla and Mehra (1973) reported chromosome number of $P$. divisum as $2 n=36$ and no detailed meiotic data is available. From the present study the status of $P$. divisum as compared to $P$. orientale is very interesting in that while both the species have $2 n=36$, the former has a pollen fertility of over $70 \%$ and in the latter it is less than $50 \%$. while they may be argued to be autotetraploids based on the formation of quadrivalents at diakinesis and metaphase I of meiosis, the difference in the percentage of functional pollen cannot be attributed to any other plausible reason than that of different genetic architecture in the two species.

Table 2. Information on pollen fretility, chromosome association and post-metaphase I irregularities at meiosis in twelve species of Pennisetum

\begin{tabular}{|c|c|c|c|c|}
\hline Species & $\begin{array}{l}\text { Chromo- } \\
\text { some } \\
\text { number } \\
(2 n)\end{array}$ & $\begin{array}{l}\text { Percentage } \\
\text { of pollen } \\
\text { fertility }\end{array}$ & $\begin{array}{l}\text { Chromosome } \\
\text { associations } \\
\text { higher than } \\
\text { bivalents }\end{array}$ & $\begin{array}{c}\text { Post } \\
\text { metaphase I } \\
\text { irregula- } \\
\text { rities }\end{array}$ \\
\hline P. americanum & 14 & 92.00 & Absent & Absent \\
\hline$P$. violaceum & 14 & 86.80 & Absent & Absent \\
\hline P. purpureum & 28 & 78.79 & Absent & Present \\
\hline$P$. mezianum & 32 & 71.70 & Present & Present \\
\hline P. hohenackeri & 18 & 66.80 & Absent & Present \\
\hline$P$. setaceum & 27 & 51.49 & Absent & Present \\
\hline$P$. divisum & 36 & 71.20 & Present & Present \\
\hline$P$. orientale & 36 & 47.40 & Present & Present \\
\hline P. clandestinum & 36 & 75.40 & Absent & Present \\
\hline P. villosum & 45 & 54.00 & Present & Present \\
\hline P. squamulatum & 54 & 68.50 & Present & Present \\
\hline P. polystachion & 54 & 36.06 & Present & Present \\
\hline
\end{tabular}

A number of polymorphic forms of $P$. orientale with a series of cytotypes or chromosomal races have been reported (Jauhar 1981, Patil et al. 1962, Sharma and De 1956). Hrishi (1952) reported a tetraploid cytotype forming 18 bivalents at first meiotic prophase and with the occasional formation of quadrivalents, while Patil et al. (1962) reported a mean of 1.66 IV per cell, and Chatterjee and Timothy (1969) reported 0-8 IVs with 3-5 IVs being most frequent at diakinesis and metaphase I. Rangaswamy (1972) observed cells with 18 IIs as well as those with 6 IVs +6 IIs. The pressent cytotype also displayed a very high frequency of quadrivalents $(99 \%$ at diakinesis and $90 \%$ at MI) which was suggestive of its autotetraploid nature.

It becomes even more conjectural to affirm the status of $P$. clandestinum with $2 \mathrm{n}=36$ chromosomes, pollen fertility reaching $75 \%$, without higher associations but with post-metaphase I abnormalities (Table 2). Hrishi (1952) reported a diploid like meiotic behaviour of this species (18 IIs) with two pairs of nucleolar organising chromosomes. Jauhar (1981) observed similar meiotic behaviour and normal pollen in several strains of this species. The present results and the reported evidences point out $P$. clandestinum to be a possible allotetraploid form with intragenomic (autosyndetic) pairing in view of the absence of multivalents. Whether the 
prevalency of only bivalents is in anyway simulative of the gene controlled meiotic system established in the hexaploid wheat (Riley and Law 1965) is a thought provoking aspect that deserves more indepth studies on its genetic architecture.

On similar lines of evaluation, $P$. villosum with $2 \mathrm{n}=45$ may be conceived as a pentaploid while $P$. squamulatum and $P$. polystachion as hexaploids $(2 \mathrm{n}=54)$ belonging to $\mathrm{x}=9$ type. In P. squamulatum, Rahman et al. (1959), reported the occurrence of 1 IV and 25 IIs while Krishnaswamy and Tulsidas (1962) observed the formation of higher associations upto hexavalents. However they suggested this species to be an allohexaploid with the constituent genomes in a less differentiated condition. Jauhar (1981) observed 25 to 27 IIs at diakinesis and metaphase I in 20 to $30 \%$ pollen mother cells and higher associations upto hexavalents and he attributes the multivalents formation to the segmental homologies of the constituent genomes as well as some of the multivalents to be the result of interchange heterozygosity present in certain populations. Occurrence of PMCs with 9 IVs and 9 IIs in the present study, as well as from that of Patil et al. (1962) is suggestive of the allopolyploid nature of this species wherein probably one genome exists in the tetraploid and the other in the diploid states.

$P$. polystachion: Tateoka (1965) reported a hexaploid cytotype of this species. Hrishi (1952) found regular meiosis in the hexaploid cytotype with 27 IIs and no multivalent formation. But the pollen sterility was $90.8 \%$ which led him to conclude it to be an allohexaploid. The present study and also that of Pantulu (1968) reveal the occurrence of hexavalents and quadrivalents in addition to the bivalents. But in both these studies, the multivalents occurred with a very low frequency. Basing on the formation of hexavlents $P$. polystachion could be classified as an autohexaploid. However, there is every possibility that the high frequency of bivalents would indicate this species to be an allohexaploid, wherein the higher associations could be the result of homeologous pairing among the chromosomes of constituent genomes. A study of meiosis in a number of collections (populations) of this species, might throw light on the fact whether the higher associations are the result of interchanges occurring in some populations or if they are due to the intergenomic pairing if it is an allohexaploid like $P$. squamulatum.

Thus, the twelve species used in the present study can be thought of in terms of 3 groups (a) those derived from ancestral forms with $\mathrm{x}=7-P$. americanum, $P$. violaceum and $P$. purpureum, (b) with $\mathrm{x}=8-P$. mezianum and (c) $\mathrm{x}=9$ all the remaining species but showing different polyploidy levels. The diversification of basic chromosome numbers in this genus has remained controversial (Pantulu 1961, Jauhar 1968) and can be thought of in two possible ways i.e. from the forms with $n=5$ to those with higher numbers like 7,8 and 9 or vice versa. In view of these controversies a multidesciplinary apporach involving genome analysis on the basis of procedures laid by Anderson (1949), comparative karyomorphology using various chromosome banding techniques, molecular aspect of genome organization as reported for $P$. americanum (Vidya and Ranjekar 1982) and other biosystematic aspects especially chemotaxonomic and palynological are needed to understand the evolutionary pattern and speciation in this genus. Some of these aspects for this set of twelve species have been studied and will be reported elsewhere. Whatever may be the basis of divergence in this genus-change in the basic chromosome number and/or polyploidy, the stabilization of a species once it became diverged from its ancestral form(s) must have been through either perennial nature and/or apomixis both of which are very common in most of the wild species of this genus.

\section{Summary}

Meiosis was studied in twelve species of Pennisetum covering three basic chromosome numbers viz. $\mathrm{x}=7,8$ and 9 . Except $P$. americanum, $P$. violaceum and $P$. hohenackeri all others were 
found to be polyploids. The auto- or allopolyploid nature of these species was discussed basing on the meiotic behaviour of the cytotypes examined. It is inferred that $P$. mezianum, $P$. divisum and $P$. orientale are autotetraploids while $P$. setaceum is an allotriploid, $P$. purpureum and $P$. clandestinum tetraploids, $P$. villosum an allopentaploid and $P$. squamulatum and $P$. polystachion allohexaploids. The possible causes for the stabilization of these species suggested.

\section{References}

Anderson, E. 1949. Introgressive Hybridization. Wiley and Sons., N. Y.

Brunken. J. N. 1977. A systematic study of Pennisetum sect. Pennisetum (Gramineae). Amer. Jour. Bot. 64: 161-176.

Chatterjiee, A. K. and Timothy, D. H. 1969. Apomixis and tetraploidy in Pennisetum orientale Rich. Crop Sci. 9: 796-799.

Christopher, J. and Abraham, A. 1976. Studies on the cytology and phylogeny of South Indian grasses III. Subfanily Panicoideae. Tribe (1) Paniceae. Cytologia 41: 621-637.

Clayton, W. D. 1972. Gramineae. p.p. 349-512. In Hepper, F. N. (ed). "Flora of West Tropical Africa", edition 2. Vol. 3. Pt. 2 Crown Agents, London.

Darlington, C. D. 1937. Recent Advances in Cytology. Churchill, London.

- and Janakiammal, E. K. 1945. Chromosome Atlas of Cultivated Plants. George Allen and Unwin Ltd., London.

Hanna, W. W. 1979. Interspecitic hybrids between millet and fountain grass. J. Hered. 10: 425-427.

Hrishi, N. J. 1952. Studies on the cytogenetics of some species of Pennisetum and their comparative morphology and anatomy. Genetica 26: 280-356.

Jauhar, P. P. 1968. Inter- and intragenomal chromosome pairing in an interspecific hybrid and its bearing on the basic chromosome number in Pennisetum. Genetica 39: 360-370.

- 1981. Cytogenetics and Breeding of Pearl Millet and Related Species. Alan R. Liss. Inc., New York.

- and Joshi, A. B. 1969. Cytotaxonomic investigations in the Panicum maximum Complex II. Cytological features, chromosome diminution and evolution of the karyotype. Cytologia 34: 222-223.

Khan, M. D. and Rahman, H. 1963. Genome relationship and chromosome behaviour in the allotriploid hybrid of $P$. typhoidis and P. purpurem. W. Pak. J. Agri. Res. 1: 61-65.

Khosla, P. K. and Mehra, P. N. 1973. IOBP chromosome number reports XLII. Taxon 22: 650-651.

Krishnaswamy, N. 1951. Origin and distribution of cultivated plants of South Asia: Millets. Indian Jour. Genet. Pl. Breed. 11 : $67-74$.

- and Rahman, V.S. 1953. Studies on the interspecific hybrid of Pennisetum typhoides Staff. Proc. 1st Sci. Workers Conf. Agri. Coll. and Res. Inst. Coimbatore. Supdt. Govt. Press. Madras (India).

— and Thulsidas, G. 1962. Meiosis in Pennisetum squamulatum Fresen. Madras Agric. Jour. 49: 55-56.

Kurup, S. 1973. Cytoembryological studies in Pennisetum hohenackeri Hochst. Mysore Univ. Sect. B. Sci. Ind. Med. Eng. 25: 1-8.

Muniamma, M. and Narayan, K. N. 1975. IOBP chromosome number reports XLVIII. Taxon 24: 367.

Narayan, K. N. 1951. Cytogenetic studies of apomixis in Pennisetum. Ph. D. Dissertation. Univ. of Calif. Berkely.

Pantulu, J. V. 1961. Cytological studies in the gnus Pennisetum with some cytological observations in the genus Cassia. Ph. D. Thesis (unpublished), Andhra Univ., Waltair, India.

- 1967. Pachytene pairing and meiosis in $F_{1}$ hybrid of Pennisetum typhoides and P. purpureum. Cytologia 32: $532-541$.

- 1968. Meiosis in two polymorphic species of Pennisetum. Curr. Sci. 38: 122-123.

— and Krishna Rao, M. 1981. Cytogenetics of pearl millet. Theor. Appl. Genet. 61: 1-17.

Patil, B. D., Hardas, M. W., O'Connor, F. K. and Vohra, S. K. 1962. Polyploidy in Pennisetum orientale Rich. Sci. 31: $161-162$.

Rahngaswamy, S. R. S. 1972. Cytological studies on diploid and polyploid taxa of the genus Pennisetum Rich. Genetica 43: 257-273.

Rahman, V. S., Chandrasekharan, P. and Krishnaswami, S. 1959. A note on some chromosome numbers in Gramineae. Curr. Sci. 29: 127-128.

-, Nair, M. K. and Krishnaswami, D. 1962. The cytology of Pennisetum rupeilii Steud.-A reinvestigation. J. G. B. S. 41 : 243-246.

Ramulu, K. S. 1968. Meiosis and fertility in derivatives of amphidiploid Pennisetum. Caryologia 21 : 147-156.

Riley, R. and Law, C. N. 1965. Genetic variation in chromosomc pairing. Adv. Genet. 13: 302-305. 
Sethi, G. S., Kalia, H. R. and Ghai, B. S. 1970. Cytogenetic studies of three interspecific hybrids between Pennisetum typhoides Stapf and Hubb. and $P$. purpureum Schumach. Cytologia 35: 96-101.

Shanthamma, C. and Narayan, K. N. 1977. Studies in Poaceae (Gramineae). J. Mysore Univ. B. 27: 302-305. Sharma, A.K. and De, D. N. 1956. Cytology of some of the millets. Caryologia 8: 294-308.

Simpson, C. E. and Bashaw, E. C. 1969. Cytology and reproductive characteristics in Penniserum setaceum. Amer. J. Bot. 56: 31-36.

Stapf, O. and Hubbard, C. E. 1934. Pennisetum. pp. 954-1070. In "Flora of Tropical Africa" (Pain D. ed.) Vol. 9. Part 6. Reeve and Co. Ltd., Ashford, Kent, England.

Stebbins, G. L. 1957. Genetics, evolution and plant breeding. Ind. Jour. Genet. Pt. Breed. 17: 129-141.

Swaminathan, M. S. and Nath, J. 1956. Two new basic chromosome numbers in the genus Peenisetum. Nature 178: $1241-1242$.

Tateoka, T. 1965. Chromosome numbers of some East African grasses. Amer. Jour. Bot. 52: 864-869.

Vidya, S. G. and Ranjekar, P. K. 1982. Genome organization in pearl millet. Ind. J. Biochem. \& Biophys. $: 167-170$. 